\title{
ДЕЙСТВИЕ КАРНОЗИНА И ЛИПОЕВОЙ КИСЛОТЫ В МОДЕЛИ ПОЗДНЕЙ СТАДИИ БОЛЕЗНИ ПАРКИНСОНА У КРЫС
}

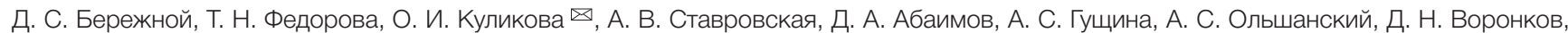
С. Л. Стволинский

Научный центр неврологии, Москва, Россия

Оценка эффективности антиоксидантных (АО) препаратов при введении на поздней стадии экспериментального паркинсонизма в условиях тотальной гибели нейронов черной субстанции (ЧС) и нарушений досаминергической иннервации стриатума является актуальной проблемой. Целью исследования было оценить эффективность АО карнозина и липоевой кислоты (ЛК) в модели поздней стадии паркинсонизма. Паркинсонизм индуцировали у крыс с помощью унилатерального стереотаксического введения 6-гидроксидофамина (ГДА) в ЧС правого полушария. АО вводили 4 раза, начиная с 14-го дня после введения токсина. Изучали влияние препаратов на поведение, гибель нейронов чС и метаболизм медиаторовмоноаминов. Оба препарата снижали развитие неврологической симптоматики и нарушения поведения, вызванные ГДА. Введение ГДА приводило к снижению уровня дофамина (ДА) и его метаболитов в правом стриатуме на 90\% (p= 0,01) и гибели более 95\% нейронов в ЧС правого полушария ( $p=0,01)$. АО значимо не влияли на количество нейронов в ЧС, но увеличивали содержание метаболитов ДА относительно животных, получавших ГДА, при этом повышение содержания ДА (в 5,8 раз; $p=0,007)$ наблюдали только у животных, получавших карнозин. Введение ЛК способствовало снижению серотонина на 23\% ( $p=0,006)$ и его метаболита 5-гидроксииндолуксусной кислоты (ГИУК) на 36\% (p = 0,009). Таким образом, при отсутствии прямого нейропротекторного эффекта было обнаружено симптоматическое действие карнозина и ЛК, что обосновывает возможность их использования в качестве дополнительной терапии болезни Паркинсона.

Ключевые слова: паркинсонизм, крысы линии Wistar, карнозин, липоевая кислота, нейромедиаторы, физиологическое тестирование

Информация о вкладе авторов: Д. С. Бережной - анализ литературы, планирование исследования, подготовка черновика рукописи и финального варианта статьи; Т. Н. Федорова - анализ литературы, планирование исследования, подготовка финального варианта статьи; О. И. Куликова анализ литературы, планирование исследования, подготовка финального варианта статьи; А. В. Ставровская - анализ литературы, планирование исследования, подготовка черновика рукописи; Д. А. Абаимов - подготовка черновика рукописи; А. С. Гущина - планирование исследования, подготовка черновика рукописи; А. С. Ольшанский - подготовка черновика рукописи; Д. Н. Воронков - подготовка черновика рукописи; С. Л. Стволинский - планирование исследования, подготовка черновика рукописи; все авторы участвовали в сборе, анализе и интерпретации данных.

Соблюдение этических стандартов: все эксперименты с животными проводили в соответствии с международными правилами работы с лабораторными животными.

Для корреспонденции: Куликова Ольга Игоревна Волоколамское ш., д. 80, г. Москва, 125367; kulikova@neurology.ru

Статья получена: 12.08.2019 Статья принята к печати: 30.08.2019 Опубликована онлайн: 18.09.2019

DOI: $10.24075 /$ vrgmu.2019.060

\section{EFFECTS OF CARNOSINE AND LIPOIC ACID IN THE LATE STAGE OF PARKINSON'S DISEASE IN RATS}

Berezhnoy DS, Fedorova TN, Kulikova OI ${ }^{\otimes}$, Stavrovskaya AV, Abaimov DA, Gushchina AS, Olshansky AS, Voronkov DN, Stvolinsky SL

Research Center of Neurology, Moscow, Russia

The late stage of Parkinson's disease is characterized by massive neuronal loss in the substantia nigra (SN) and degeneration of the dopaminergic innervation in the striatum. There is a need to assess the neuroprotective effect of antioxidants (AO) at this stage of the disease. The aim of our study was to assess the efficacy of two $\mathrm{AO}$, carnosine and lipoic acid $(\llcorner\mathrm{A})$, in the rat model of late-stage parkinsonism. The pathology was induced by a unilateral injection of 6 -hydroxydopamine (6-OHDA) into the SN of the right brain hemisphere. AO were administered 4 times, starting on day 14 following the injection of the toxin. We investigated the effect of the injected drugs on the behavior of rats, the loss of neurons in the SN and the metabolism of biogenic neurotransmitter amines. Both $\mathrm{AO}$ dampened the development of 6-OHDA-induced neurological and behavioral symptoms. 6-OHDA induced a 90\% drop ( $p=0.01)$ in the levels of dopamine (DA) and its metabolites in the right striatum and caused death of over $95 \%$ of neurons $(p=0.01)$ in the SN of the right hemisphere $(p=0.01)$. AO did not have a significant effect on the number of neurons in the SN but caused an increase in the levels of DA metabolites, as compared to their levels in the animals exposed to 6-OHDA. Elevated DA (a 5.8-fold increase, $p=0.007$ ) was observed only in the animals treated with carnosine. LA stimulated a $23 \%$ decline in serotonin levels $(p=0.06)$ and a $36 \%$ increase $(p=0.009)$ in its metabolite, 5 -hydroxyindolacetic acid $(5-H I A A)$. We conclude that although carnosine and LA did not have a direct neuroprotective effect, they could relieve the symptoms. This suggests that these AO could be used as an adjunctive component to antiparkinsonian therapy.

Keywords: parkinsonism, Wistar rats, carnosine, lipoic acid, neurotransmitters, behavioral tests

Author contribution: Berezhnoy DS analyzed the literature; planned the study; acquired, analyzed and interpreted the obtained data; prepared the draft of the manuscript and revised its final version. Fedorova TN analyzed the literature; planned the study; analyzed and interpreted the obtained data; revised the manuscript. Kulikova Ol analyzed the literature; planned the study; acquired, analyzed and interpreted the obtained data; revised the manuscript. Stavrovskaya $\mathrm{AV}$ analyzed the literature; planned the study; acquired, analyzed and interpreted the obtained data; prepared the draft of the manuscript. Abaimov DA acquired, analyzed and interpreted the obtained data; prepared the draft of the manuscript. Gushchina AS planned the study; acquired, analyzed and interpreted the obtained data; prepared the draft of the manuscript. Olshansky AS acquired and analyzed the data; prepared the draft of the manuscript. Voronkov DN acquired analyzed and interpreted the obtained data; prepared the draft of the manuscript. Stvolinsky SL planned the study; acquired, analyzed and interpreted the obtained data; prepared the draft of the manuscript.

Compliance with ethical standards: all experiments involving the use of animals were conducted in full compliance with the international Guide for the Care and Use of Laboratory Animals.

Correspondence should be addressed: Olga I. Kulikova

Volokolamskoe shosse, 80, Moscow, 125367; kulikova@neurology.ru

Received: 12.08.2019 Accepted: 30.08.2019 Published online: 18.09.2019

DOI: 10.24075/brsmu.2019.060 
Болезнь Паркинсона (БП) - это прогрессирующее нейродегенеративное заболевание, характеризующееся гибелью дофаминергических нейронов в компактной части черной субстанции (кчЧС). В настоящее время основные методы терапии БП симптоматические и остается актуальным поиск нейропротекторных препаратов, способных замедлить или остановить течение данного заболевания [1, 2].

Наиболее часто в качестве модели паркинсонизма на животных используют токсическую модель с введением 6-гидроксидофамина (ГДА) - селективного катехоламинергического нейротоксина, действующего как прямой источник свободнорадикальных соединений и блокатор комплексов I и IV электронтранспортной цепи митохондрий [3]. Введение крысам ГДА в область 40 приводит практически к полной гибели дофаминергических нейронов и их терминалей в стриатуме в течение первых 10-14 дней [4]. Применение антиоксидантных (АО) препаратов как до введения ГДА, так и сразу после операции, показывает их эффективность и наличие существенного нейропротекторного эффекта [5]. Это может быть связано с их прямым действием на образующиеся в результате окисления ГДА свободные радикалы и, отчасти, с влиянием на сам процесс аутоокисления ГДА [6]; при этом действие АО направлено скорее не на предотвращение развития патологии, а на инактивацию самого токсина как этиологического фактора.

В условиях моделирования ранней стадии паркинсонизма у крыс эффективное протекторное действие проявили АО-препараты карнозин и альфалипоевая кислота (ЛК) [7]. В то же время представляет интерес оценка их эффективности при введении на более поздней стадии, когда уже произошла гибель нейронов и проявились нарушения в дофаминергической иннервации стриатума, что соответствует времени постановки диагноза и началу лечения пациентов с БП.

В связи с этим целью данного исследования было оценить влияние карнозина и ЛК на поведение и нейрохимические показатели ткани мозга крыс в модели поздней стадии паркинсонизма, индуцированного ГДА.

\section{МАТЕРИАЛЫ И МЕТОДЫ}

Исследование проводили на 40 аутбредных крысах-самцах линии Wistar в возрасте 3 месяцев и массой тела 250-300 г, содержавшихся в стандартных контролируемых условиях вивария при 12-часовом световом цикле и свободном доступе к воде и пище.

Bcex животных разделили на четыре группы: ложнооперированные животные $(n=9)$, получавшие эквивалентный объем растворителя (0,05\% аскорбиновой кислоты), - группа «контроль» и животные трех экспериментальных групп, которым в начале исследования вводили в ЧС ГДА (Sigma; США) в дозе 12 мкГ в 3 мкл 0,05\%-го раствора аскорбиновой кислоты в соответствии с координатами атласа мозга крыс $(A P=-4,8 ; L=1,9$; $V=8,0)$ [8]. Для анестезии применяли золетил 100 в дозе 3 мг/100 г и ксиланит в дозе 3 мг/кг массы тела внутримышечно; для премедикации использовали атропин в дозе 0,04 мг/кг массы тела подкожно за 10-15 мин до введения ксиланита. На 14-, 16-, 18- и 20-й дни после введения токсина животные первой группы $(n=9)$ получали внутрибрюшинно инъекции 0,9\%-го раствора $\mathrm{NaCl}$ («ГДА + 0,9\% NaCl»); второй и третьей групп ( $n=11$ и $n=11)$ исследуемые вещества: карнозин дозой 50 мг/кг массы тела (Свидлайт АБ; Швеция) («ГДА + карнозин») и ЛК дозой 50 мг/Кг массы тела (Chem-Implex Int'l Inc.; США) («ГДА + ЛК») соответственно.

На 21- и 22-й дни после введения токсина проводили физиологическое тестирование животных в тестах "Открытое поле» (ОП) и “сужающаяся дорожка» (СД). Поскольку не все животные были способны пройти тест СД до конца, поведение животных на дорожке дополнительно оценивали по специальной шкале неврозоподобного состояния (табл. 1) [9]. На 25-й день эксперимента животных умерщвляли при помощи гильотины (НПК Открытая Наука; Россия) и извлекали на льду мозг, из которого выделяли дорсальный стриатум левого и правого полушарий для последующего биохимического анализа и фрагмент среднего мозга, содержащий ЧС, - для

Таблица 1. Балльная оценка неврозоподобного состояния животных в тесте “сужающаяся дорожка». Представлен вид активности, разные его варианть и соответствующие баллы

\begin{tabular}{|c|c|c|}
\hline Вид активности & Элементы & Балл \\
\hline \multirow{5}{*}{ Груминг } & Нос-щеки & 1 \\
\hline & Нос-щеки-уши & 2 \\
\hline & Нос-щеки-уши-живот & 3 \\
\hline & Нос-щеки-уши-живот-спина & 4 \\
\hline & -//- + покусывания & 5 \\
\hline \multicolumn{3}{|l|}{ Движение } \\
\hline \multirow{4}{*}{ Головой } & Обнюхивание & 1 \\
\hline & Влево-вправо & 2 \\
\hline & Жевание & 3 \\
\hline & Лизание & 3 \\
\hline \multirow{3}{*}{ Телом } & Поворот & 3 \\
\hline & Пячение & 4 \\
\hline & Замирание & 5 \\
\hline \multirow{2}{*}{ Свешивание } & Голова & 1 \\
\hline & Половина тела & 2 \\
\hline Остановка на дорожке & & 3 \\
\hline Соскальзывание с дорожки & & 2 \\
\hline Икота & & 4 \\
\hline
\end{tabular}


иммуногистохимического окрашивания. Полученные образцы хранили в жидком азоте.

\section{Количественная оценка дофаминергических нейронов}

Количественную оценку дофаминергических нейронов в области ЧС животных контрольной группы и группы «ГДА + $\mathrm{NaCl»} \mathrm{проводили} \mathrm{с} \mathrm{помощью} \mathrm{специфического}$ иммуногистохимического окрашивания тирозингидроксилазь (ТГ), ключевого фермента синтеза дофамина, иммуносрлуоресцентным методом [10]. Образцы, фиксированные 4\%-м формалином, пропитывали сахарозой, заключали в среду ОСТ Tissue Tek (Sigma; США) и готовили замороженные фрронтальные срезы толщиной 12 мкм в области ЧС. Срезы инкубировали 24 ч с поликлональными кроличьими антителами к тирозингидроксилазе (Т8700; Sigma; США) в разведении $1: 800$ во влажной камере при комнатной температуре. Связывание первичных антител визуализировали при помощи козьих антител, меченых флуорохромом CF488, выработанных против иммунглобулинов кролика (1: 500; Sigma; США). Срезы заключали под покровное стекло в среду FluoroShield (Sigma; США) и фотографировали (не менее 8-10 срезов у животного с интервалом 36-48 мкм) под микроскопом Nikon Eclipse Ni-u (Nikon; CША), при увеличении объектива ×10. Тела нейронов подсчитывали на поле зрения в программе ImageJ ( $\mathrm{NIH}$; США).

\section{Содержание основных нейромедиаторных аминов и их метаболитов}

Содержание основных нейромедиаторных аминов и их метаболитов: дофамина (ДА), 3,4-дигидроксифенилуксусной кислоты (ДОФУК), гомованилиновой кислоты (ГВК), 3-метокситирамина (3-МТ), норадреналина (НА), серотонина (5-ОТ) и 5-гидроксииндолуксусной кислоты (5-ГИУК) оценивали в стриатуме левого и правого полушарий с помощью метода высокоэффективной жидкостной хроматографии с электрохимической детекцией (ВЭЖХ/ЭД) на жидкостном хроматограсре System Gold (Beckman Coulter Inc.; США), оснащенном амперометрическим детектором RECIPE EC 3000 (Recipe GmbH; Германия). Ткань мозга гомогенизировали в 20 объемах 0,1 N HClO4 с добавлением диоксибензиламина (0,5 нмоль/мл) в качестве внутреннего стандарта, затем центрифугировали при 10000 g в течение 10 мин, для анализа использовали супернатант [7].

\section{Статистическая обработка данных}

Использовали программу Statistica 10.0 (Dell. Inc.; США). Статистическую значимость различий определяли с помощью факторного дисперсионного анализа (ANOVA) и HSD теста Tukey для post hoc анализа. Попарное сравнение выборок проводили с использованием $t$-теста Стьюдента и $U$-критерия Манна-Уитни в зависимости от нормальности распределения значений. Различия считали значимыми при $p<0,05$. Результаты представляли в виде среднего значения \pm стандартная ошибка среднего $(\mathrm{M} \pm m)$.

\section{РЕЗУЛЬТАТЫ}

\section{Анализ неврологической симптоматики}

Результаты теста СД показали наличие выраженных нарушений у животных, которым был введен ГДА $(F(3,36)=$ $10,54 ; p=0,001)$. В контрольной группе все животные проходили по дорожке в среднем за 13,88 \pm 1,73 с, среди животных в группе «ГДА + NaCl» только 3 из 11 животных смогли пройти тест до конца. Остальные животные демонстрировали замирание и не справлялись с тестом за отведенное время. В связи с этим в качестве интегральной характеристики по данному тесту использовали балльную оценку неврозоподобного состояния (табл. 2). В обеих группах у животных, получавших карнозин или ЛК, выраженных нарушений в поведении не было отмечено, и по результатам post hoc анализа обе группы не отличались от контрольных животных, но значимо отличались от группы «ГДА + $\mathrm{NaCl}$ (табл. 2).

Оценка поведения животных в тесте ОП не выявила значимых изменений горизонтальной активности среди всех экспериментальных групп $(F(3,36)=1,83 ; p=0,16)$, однако попарное сравнение показало значимые различия между группами «контроль» и «ГДА + NaCl» $(7,97 \pm$ 0,42 и 4,21 \pm 0,77; $p=0,001)$. Результаты дисперсионного анализа показали изменения вертикальной активности животных $(F(3,36)=3,04 ; p=0,04)$. По результатам апостериорного анализа по этому параметру, среди всех экспериментальных групп вертикальная активность была значимо снижена только в группе «ГДА + 0,9\% $\mathrm{NaCl}$ », но не у животных, получавших карнозин или ЛК (табл. 2).

\section{Количество дофаминергических нейронов}

Количество дофаминергических нейронов в кччС определяли по иммуногистохимической локализации маркера дофаминовых нейронов тирозингидроксилазы. Окрашивание срезов среднего мозга на фермент тирозингидроксилазу выявило гибель нейронов у всех животных, которым вводился ГДА $(F(3,10)=6,33$; $p=0,01$ ) (рис. 1), и отсутствие эффектов вводимых антиоксидантных препаратов $(F(2,8)=0,51 ; p=0,61)$. Так, если у контрольных животных в исследуемой области кчЧС насчитывали в среднем $166 \pm 48$ нейронов, то у животных всех экспериментальных групп, которым вводили ГДА, $4 \pm 2, p=0,01$. Полученные данные подтверждают релевантность используемой модели.

Таблица 2. Влияние карнозина и липоевой кислоты (ЛК) на основные параметры поведения экспериментальных животных в тестах «сужающаяся дорожка» (СД) и «открытое поле» (ОП). Приведены результаты post hoc сравнений, выполненных с помощью HSD теста Tukey

\begin{tabular}{|l|c|c|c|}
\hline & Оценка прохождения СД (баллы) & Горизонтальная активность в ОП (м) & Вертикальная активность в ОП (стойки, шт.) \\
\hline Контроль & $5,13 \pm 0,64$ & $7,97 \pm 0,42$ & $11,88 \pm 1,61$ \\
\hline «ГДА + NaCl» & $13,60 \pm 1,53 \#$ & $4,21 \pm 0,77$ & $4,20 \pm 1,52 \#$ \\
\hline «ГДА + Карнозин» & $7,18 \pm 1,05^{*}$ & $6,32 \pm 1,38$ & $8,64 \pm 1,50$ \\
\hline «ГДА + ЛК» & $5,27 \pm 1,27^{*}$ & $6,16 \pm 1,14$ & $9,90 \pm 2,29$ \\
\hline
\end{tabular}

Примечание: * - значимые отличия от группы «ГДА + NaCl», p<0,05; \# - значимые отличия от контрольной группы, $p<0,05$ 


\section{Определение содержания медиаторов-моноаминов и их метаболитов}

Факторный анализ содержания моноаминов и их метаболитов в стриатуме экспериментальных животных показал наличие изменений только в правом полушарии, в которое производили введение токсина $(F(21,81)=3,29$; $p=0,001)$, но не в левом $(F(21,69)=1,15 ; p=0,32)$. Однако попарное сравнение групп «ГДА + NaCl» с контролем выявило значимое повышение уровня ДОФУК (на 19,0 \pm 5,3\%) и ГВК (на 19,1 \pm 3,8\%) в левом полушарии при введении ГДА (рис. 2); при этом карнозин снижал ДОФУК до уровня контрольной группы.

В результате анализа содержания моноаминов в стриатуме правого полушария, у всех животных, которым вводили токсин, вне зависимости от терапии, наблюдали значительное снижение содержания ДА и его основных метаболитов (в среднем на 90\%) (рис. 3). Интермедиат 3-МТ снижался менее интенсивно (в среднем на 58\%).

Статистически значимых изменений в содержании серотонина выявлено не было, а концентрация его метаболита ГИУК в этих условиях достоверно увеличилась (на 38\%) по сравнению с контролем (рис. 4).

Достоверное увеличение содержание ДА в стриатуме (в 5,8 раза, $p=0,007$ ) по сравнению с группой «ГДА + NaCl» наблюдали только у животных, получавших карнозин. При этом содержание метаболитов ДА (ДОФУК и ГВК) увеличивалось при введении карнозина в 3,4 ( $p=0,04)$ и 8,8 ( $p=0,01)$ раза, а при введении ЛК в 4,7 ( $p=0,03)$ и 7,4 ( $p=0,04)$ раза соответственно (рис. 3). Влияния исследуемых препаратов на уровень 3-МТ отмечено не было. Содержание серотонина и его метаболита ГИУК в группе, получавшей ЛК, снижалось примерно на 23\% $(p=0,006)$ и 36\% ( $p=0,009)$ соответственно по отношению к группе «ГДА + NaCl». Карнозин не оказывал влияния на содержание серотонина и его метаболитов.

\section{ОБСУЖДЕНИЕ РЕЗУЛЬТАТОВ}

Проведена комплексная оценка влияния АО карнозина и ЛК на поведение животных в фризиологических тестах и на метаболизм ДА и серотонина в нервной ткани стриатума на модели паркинсонизма у крыс. Паркинсонизм индуцировали унилатеральным введением ГДА в ЧС, с инъекцией AO, начиная с 14-го дня после операции, чтобы исключить их влияние на аутоокисление токсина и процессы гибели нейронов, происходящие ранее.

Гибель нейронов и денервация ипсилатерального стриатума были подтверждены методом иммуногистохимического окрашивания дофаминергических нейронов ЧС и значительным снижением уровня ДА и его метаболитов в стриатуме правого полушария, в которое вводили токсин, при этом вне зависимости от терапии, уровень ДА и его метаболитов оставался сниженным относительно контроля. В то же время карнозин и ЛК повлияли на метаболизм ДА, увеличив содержание его метаболитов относительно группы животных, получавших токсин, при этом достоверное повышение содержания самого ДА наблюдали только в группе животных, получавших карнозин. Введение ЛК способствовало снижению серотонина и его метаболита ГИУК относительно группы, получавшей токсин. Учитывая,
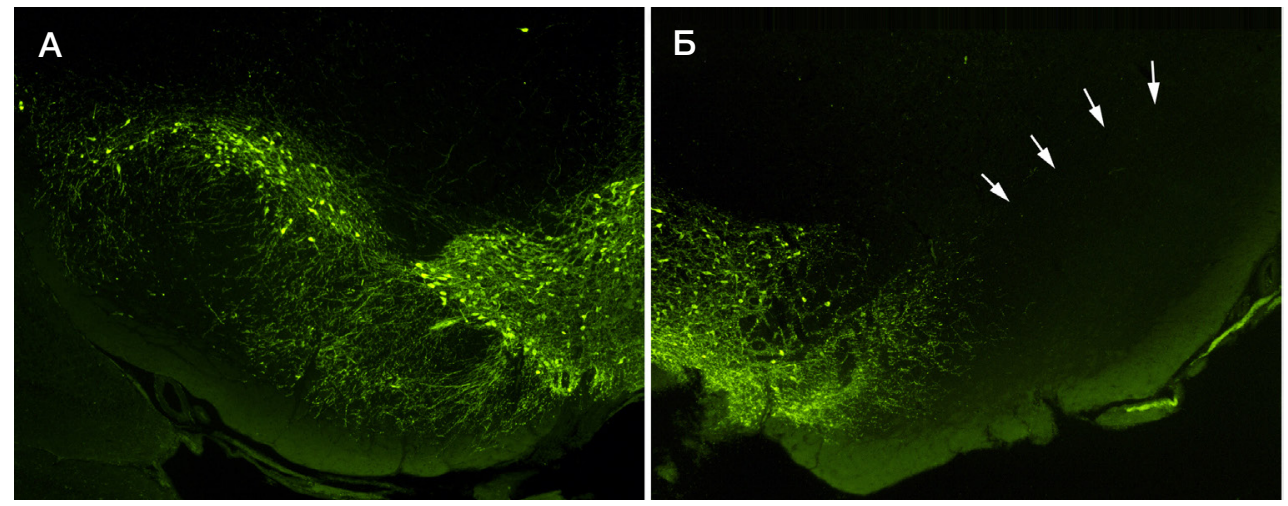

Рис. 1. Иммунофлуоресцентное выявление тирозингидроксилазы в ЧС при одностороннем интранигральном введении 6-гидроксидофамина. А. Левое полушарие, введение физиологического раствора. Б. Правое полушарие, введение ГДА (стрелками показана поврежденная область ЧС, лишенная дофаминовых нейронов; ув. об. х10)
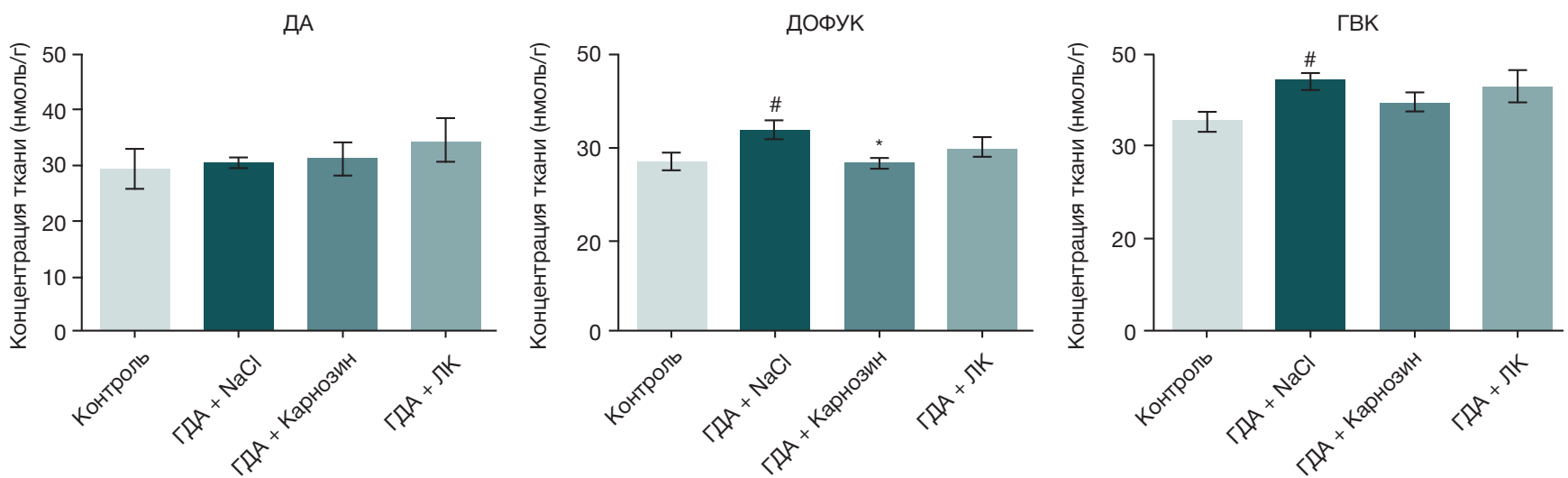

Рис. 2. Влияние карнозина и липоевой кислоты (ЛК) на содержание дофамина (ДА), 3,4-дигидроксифенилуксусной кислоты (ДОФУК) и гомованилиновой кислоты (ГВК) в стриатуме левого полушария. \# - достоверные отличия от контрольной группы, $p<0,05$; * - достоверные отличия от группы «ГДА + NaСl», $p<0,05$ 

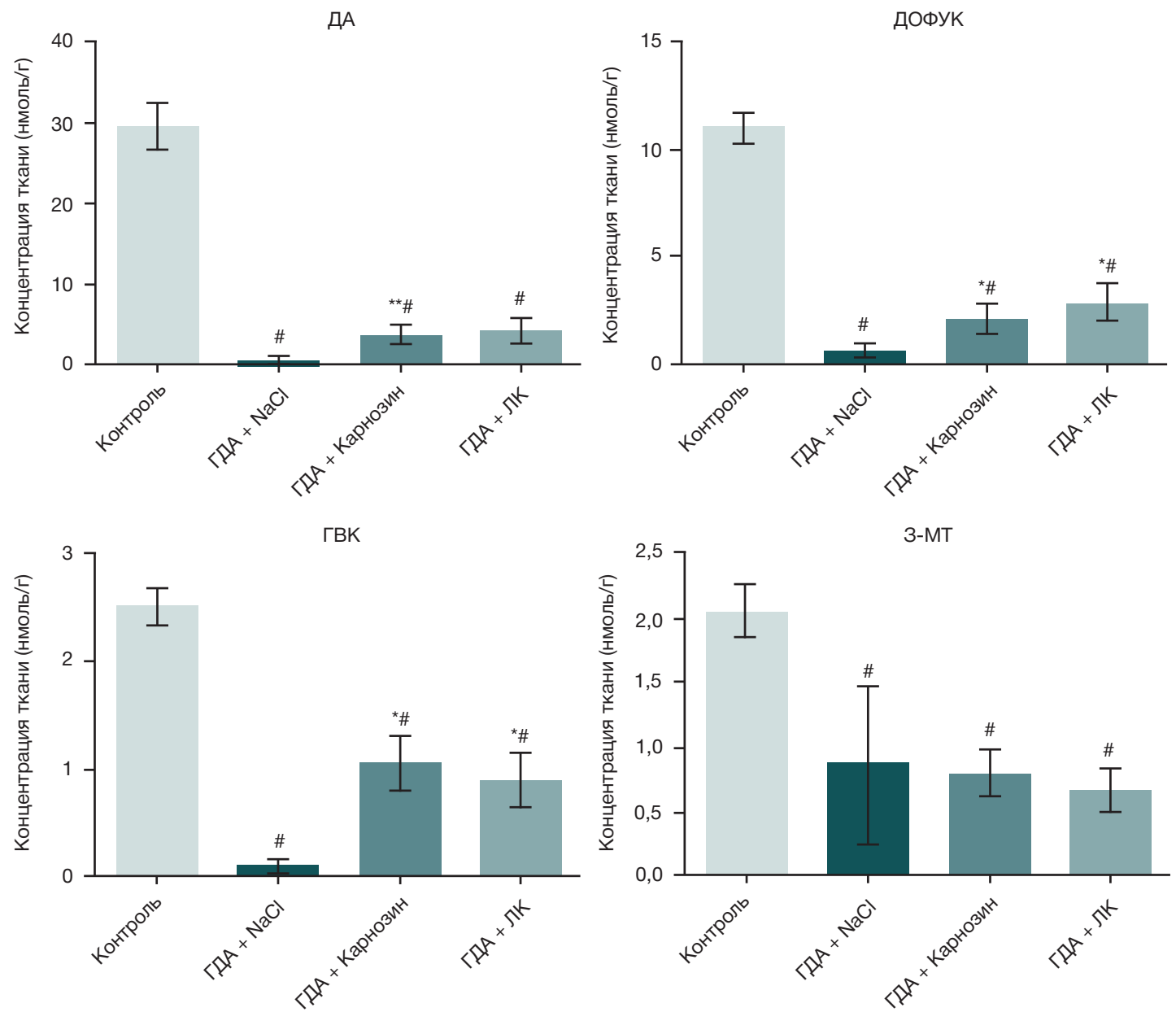

Рис. 3. Влияние карнозина и липоевой кислоты (ЛК) на содержание дофамина (ДА), 3,4-дигидроксифенилуксусной кислоты (ДОФУК), гомованилиновой кислоты (ГВК) и 3-метокситирамина (3-МТ) в стриатуме правого полушария. \# — достоверные отличия от контрольной группы, $p<0,05 ;{ }^{*}-$ достоверные отличия от группы «ГДА $+\mathrm{NaCl}, p<0,05 ;{ }^{* \star}-p<0,01$
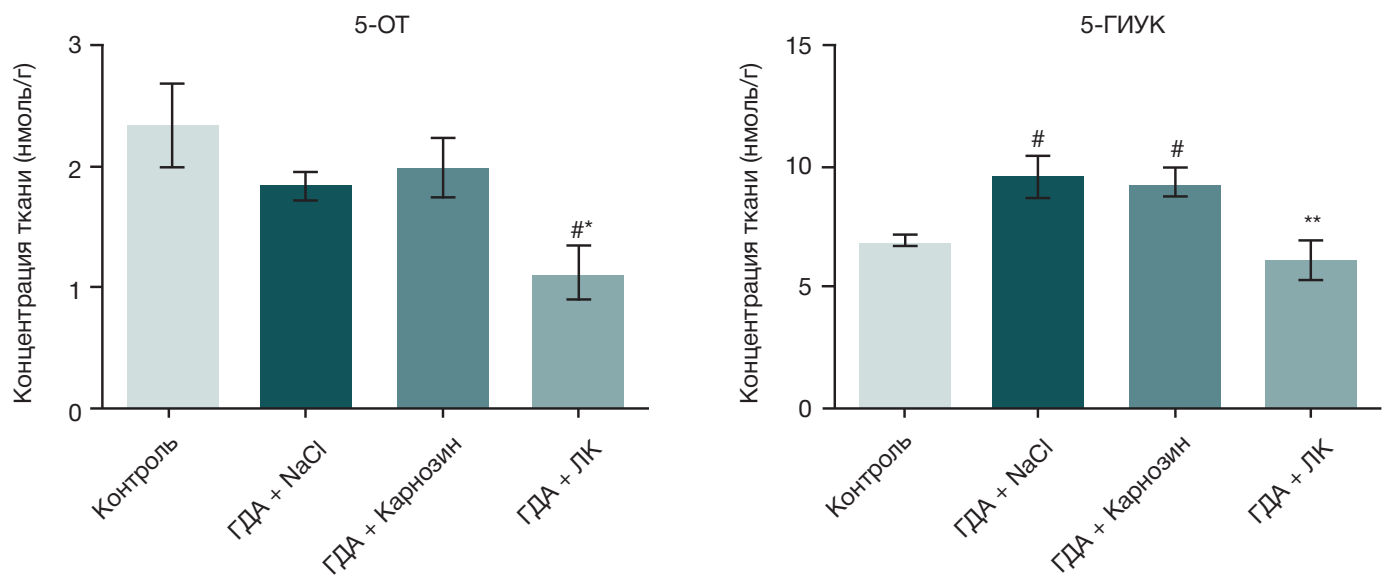

Рис. 4. Влияние карнозина и липоевой кислоты (ЛК) на содержание серотонина (5-ОТ) и 5-гидроксииндолуксусной кислоты (5-ГИУК) в стриатуме правого полушария. \# - достоверные отличия от контрольной группы, $p<0,05$; * - достоверные отличия от группы «ГДА + NaCl», $p<0,05$; ** - $p<0,01$

что серотонин усиливает активность нейрохимических механизмов двигательных нарушений при БП, а снижение серотонинергической нейротрансмиссии в системе базальных ядер головного мозга, напротив, оказывает антипаркинсонический эффект [11], установленное влияние ЛК на серотонинергическую иннервацию может вносить определенный вклад в устранение двигательных нарушений при паркинсонизме.

Физиологическое тестирование выявило снижение паркинсоноподобной неврологической симптоматики и значительно менее выраженные поведенческие нарушения у животных, получавших оба АО-препарата. Четырехкратное введение как карнозина, так и ЛК на 14-20-й дни эксперимента предотвращало развитие неврозоподобного состояния животных, вызванного ГДА.

На экспериментальных моделях токсин-индуцированного паркинсонизма у крыс показаны положительные нейропротекторные эффекты как карнозина [12], так и липоевой кислоты [13]. Оба препарата восстанавливали антиоксидантный статус мозга, снижали уровень перекисного окисления, а липоевая кислота также увеличивала двигательную активность животных [13]. 
Однако в данных исследованиях препараты вводились одновременно с токсином, и не была проведена оценка гибели нейронов ЧС. Это осложняет интерпретацию полученных результатов и оставляет открытым вопрос о механизмах действия данных соединений. Проведенное нами исследование позволяет обоснованно судить о симптоматических эффектах применения данных препаратов на поздних сроках развития экспериментального паркинсонизма.

В целом, полученные данные указывают на целесообразность применения изученных антиоксидантных препаратов в дополнение к базисной терапии паркинсонизма. Ранее уже было предложено использование липоевой кислоты в качестве дополнительной терапии к леводопе [14], а для сочетанного применения карнозина с леводопой даже была показана клиническая эфффективность [15].

\section{ВЫВОДЬ}

При отсутствии прямого нейропротекторного эффекта нами было обнаружено значимое симптоматическое действие карнозина и ЛК, механизм которого связан с компенсаторным увеличением содержания ДА и его метаболитов и одновременным снижением уровня серотонина. В целом, полученный эффект предполагает возможность использования изученных антиоксидантов в качестве дополнительной симптоматической терапии БП.

\section{Литература}

1. Sarkar S, Raymick J, Imam S. Neuroprotective and Therapeutic Strategies against Parkinson's Disease: Recent Perspectives. Int J Mol Sci. 2016; 17 (6): E904. DOI: 10.3390/ijms17060904. PMID: 27338353

2. Иллариошкин С. Н., Сломинский П. А., Шадрина М. И., Багыева Г. Х., Загоровская Т. Б., Маркова Е. Д. и др. Гетерогенность спорадической болезни паркинсона: молекулярный подход к решению проблемы. Анналь клинической и экспериментальной неврологии. 2007; 1 (1): 23-31.

3. Mazzio EA, Reams RR, Soliman KF. The role of oxidative stress, impaired glycolysis and mitochondrial respiratory redox failure in the cytotoxic effects of 6-hydroxydopamine in vitro. Brain Research. 2004; 1004 (1): 29-44.

4. Jeon BS, Jackson-Lewis V, Burke RE. 6-Hydroxydopamine lesion of the rat substantia nigra: time course and morphology of cell death. Neurodegeneration. 1995: 4 (2): 131-7.

5. Zbarsky V, Datla KP, Parkar S, Rai DK, Aruoma OI, Dexter DT Neuroprotective properties of the natural phenolic antioxidants curcumin and naringenin but not quercetin and fisetin in a 6-OHDA model of Parkinson's disease. Free Radic Res. 2005; 39 (10): 1119-25. PMID: 7583676.

6. Soto-Otero R, Mendez-Alvarez E, Hermida-Ameijeiras A, Muñoz-Patiño AM, Labandeira-Garcia JL. Autoxidation and neurotoxicity of 6-hydroxydopamine in the presence of some antioxidants: potential implication in relation to the pathogenesis of Parkinson's disease. J Neurochem. 2000; 74 (4): 1605-12. DOI: 10.1046/j.1471-4159.2000.0741605.x. PMID: 10737618.

7. Kullikova OI, Berezhnoy DS, Stvolinsky SL, Lopachev AV, Orlova VS, Fedorova TN. Neuroprotective effect of the carnosine - alphalipoic acid nanomicellar complex in a model of early-stage Parkinson's disease. Regul Toxicol Pharmacol. 2018; 95: 254-9. DOI: 10.1016/j.yrtph.2018.03.025. PMID: 2960191

\section{References}

1. Sarkar S, Raymick J, Imam S. Neuroprotective and Therapeutic Strategies against Parkinson's Disease: Recent Perspectives. Int J Mol Sci. 2016; 17 (6): E904. DOI: 10.3390/ijms17060904. PMID: 27338353

2. Illarioshkin SN, Slominsky PA, Shadrina MI, Bagyeva GKh, Zagorovskaya TB, Markova ED, et al. The heterogeneity of sporadic Parkinson's disease: a molecular approach to solving a problem. Annaly Klinicheskoy I Experimental'noy Nevrologii. 2007; 1 (1): 23-31. Russian.

3. Mazzio EA, Reams RR, Soliman KF. The role of oxidative stress, impaired glycolysis and mitochondrial respiratory redox failure in the cytotoxic effects of 6-hydroxydopamine in vitro. Brain Research. 2004; 1004 (1): 29-44.

4. Jeon BS, Jackson-Lewis V, Burke RE. 6-Hydroxydopamine lesion of the rat substantia nigra: time course and morphology of
8. Paxinos G, Watson C. The Rat Brain in Stereotaxic Coordinates. 6th Edition. San Diego: Academic Press, 2006. 456 p.

9. Болотова В. Ц., Крауз В. А., Шустов Е. Б. Биологическая модель экспериментального невроза у лабораторных животных. Биомедицина. 2015; (1): 66-80.

10. Худоерков Р. М., Воронков Д. Н., Дикалова Ю. В. Количественная морфохимическая характеристика нейронов черной субстанции мозга крысы и ее объемная реконструкция. Бюллетень экспериментальной биологии и медицины. 2013; 156 (6): 861-4.

11. Крыжановский Г. Н., Магаева С. В., Трекова Н. А., Ветрилэ Л. А., Башарова Л. А., Атаджанов М. А. Участие серотонинергического аппарата стриатума в паркинсоническом синдроме. Бюлл. эксперим. биол. и медицины. 1993; (5): 466-9.

12. Zhao J, Shi L, Zhang LR. Neuroprotective effect of carnosine against salsolinol-induced Parkinson's disease. Exp Ther Med. 2017; 14 (1): 664-70.

13. de Araujo DP, De Sousa CN, Araujo PV, Menezes CE, Sousa Rodrigues FT, Escudeiro S S, et al. Behavioral and neurochemical effects of alpha-lipoic Acid in the model of Parkinson's disease induced by unilateral stereotaxic injection of 6-OHDA in rat. Evid Based Complement Alternat Med. 2013; (1): 571-8.

14. Di Stefano A, Sozio P, Cocco A, lannitelli A, Santucci E, Costa M, et al. L-dopa- and dopamine-(R)-alpha-lipoic acid conjugates as multifunctional codrugs with antioxidant properties. J Med Chem. 2006; 49 (4): 1486-93.

15. Федорова Т. Н., Багыева Г. Х., Степанова М. С., Добротворская И. С., Иванова-Смоленская И. А., Полевая Е. В. и др. Эффективность карнозина при болезни Паркинсона. Неврологический вестник. 2009; 41 (1): 24-9. cell death. Neurodegeneration. 1995: 4 (2): 131-7.

5. Zbarsky V, Datla KP, Parkar S, Rai DK, Aruoma OI, Dexter DT. Neuroprotective properties of the natural phenolic antioxidants curcumin and naringenin but not quercetin and fisetin in a 6-OHDA model of Parkinson's disease. Free Radic Res. 2005; 39 (10): 1119-25. PMID: 7583676.

6. Soto-Otero R, Mendez-Alvarez E, Hermida-Ameijeiras A, Muñoz-Patiño AM, Labandeira-Garcia JL. Autoxidation and neurotoxicity of 6-hydroxydopamine in the presence of some antioxidants: potential implication in relation to the pathogenesis of Parkinson's disease. J Neurochem. 2000; 74 (4): 1605-12. DOI: 10.1046/i.1471-4159.2000.0741605.x. PMID: 10737618.

7. Kulikova Ol, Berezhnoy DS, Stvolinsky SL, Lopachev AV, Orlova VS, Fedorova TN. Neuroprotective effect of the carnosine - alphalipoic acid nanomicellar complex in a model of early-stage 
Parkinson's disease. Regul Toxicol Pharmacol. 2018; 95: 254-9. DOI: 10.1016/j.yrtph.2018.03.025. PMID: 2960191.

8. Paxinos G, Watson C. The Rat Brain in Stereotaxic Coordinates 6th Edition. San Diego: Academic Press, 2006. 456 p.

9. Bolotova VTs, Krauz VA, Shustov EB. Biological model of experimental neurosis in laboratory animals. Biomedicina. 2015 (1): 66-80. Russian.

10. Khudoerkov RM, Voronkov DN, Dikalova YuV. Quantitative morphochemical characteristics of the neurons of the rat brain's substantia nigra and its volume reconstruction. Bull experiment biol and medicine. 2013; 156 (6): 861-4. Russian.

11. Kryzhanovsky GN, Magaeva SV, Trekova HA, Vetrila LA, Basharova LA, Atadzhanov MA. Participation of the serotonergic apparatus of the striatum in the Parkinsonian syndrome. Bull experiment bio and medicine. 1993; (5): 466-9. Russian.
12. Zhao J, Shi L, Zhang LR. Neuroprotective effect of carnosine against salsolinol-induced Parkinson's disease. Exp Ther Med. 2017; 14 (1): 664-70.

13. de Araujo DP, De Sousa CN, Araujo PV, Menezes CE, Sousa Rodrigues FT, Escudeiro S S, et al. Behavioral and neurochemical effects of alpha-lipoic Acid in the model of Parkinson's disease induced by unilateral stereotaxic injection of 6-OHDA in rat. Evid Based Complement Alternat Med. 2013; (1): 571-8.

14. Di Stefano A, Sozio P, Cocco A, lannitelli A, Santucci E, Costa M, et al. L-dopa- and dopamine-(R)-alpha-lipoic acid conjugates as multifunctional codrugs with antioxidant properties. J Med Chem. 2006; 49 (4): 1486-93

15. Fedorova TN, Bagieva GH, Stepanova MS, Dobrotvorskaya MS, Ivanova-Smolenskaya IA, Polevaya EV, et al. Effectivity of carnosine in Parkinson's disease. Neurological bull. 2009; 41 (1): 24-9. Russian. 